قسم أمر اض الحيوان جامعة البعث - سورية

\title{
DETECTION OF CLOSTRIDIUM CHAUVOEI EFFECT ON COWS CARCASSES MEAT IN MIDDLE REGION'S SLAUGHTERHOUSES IN SYRIA
}

(With 4 Tables and 4 Figures)
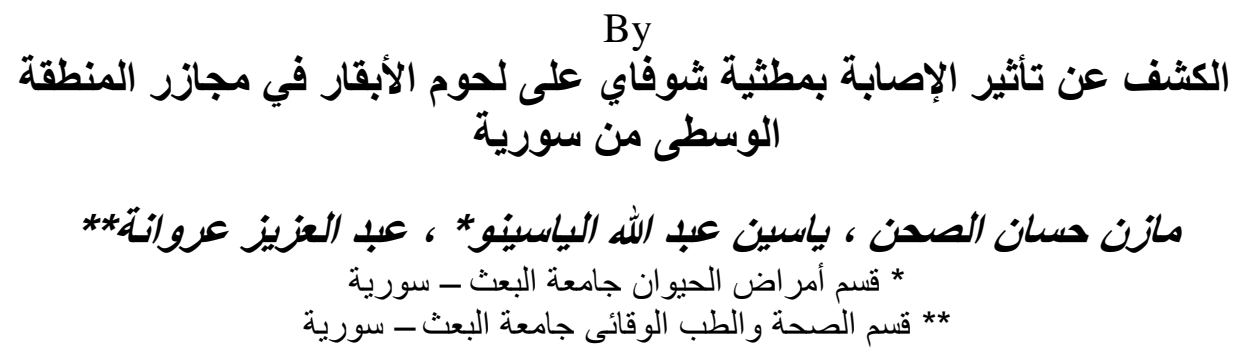

(Received at 15/11/2009)

تم من خلال هذا البحث الكثف عن تأثثر الإصـابة بمطنية شوفاي (مرض القائمة السوداء) على لحوم الأبقار في مجازر المنطقة الوسطى من سورية من حيث جودة اللحوم وصلاحيتها للاستهلاك البشري وقر ار فحصها. حيث أجري البحث على على عينات من ذبائح أبقار مشتبه

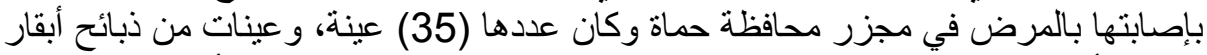

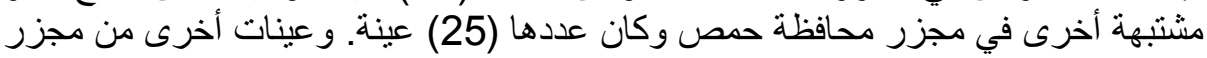

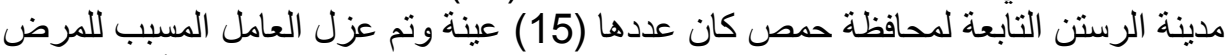

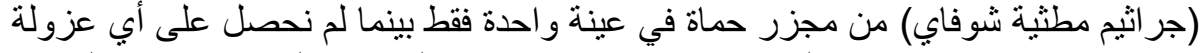

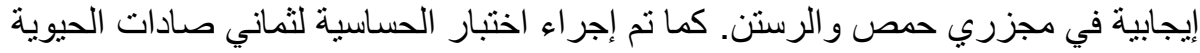
على العزولات الإيجابية لتحديد نوع الصاد الحيوي المناسب لعلاج الإصـابة بمرض الجية الجمرة العرضية.

\section{SUMMARY}

In this study, the effect of black leg disease was detected on cattle's meat in middle region's slaughterhouses in Syria at which meat's goodness and its suitability for human's use and its inspection decision were evaluated. This research was applied on samples from cattle carcasses (75) suspected to be infected by black leg disease in Hama's slaughterhouse (35) samples, Homs's slaughterhouse (25) samples, and Rastan's slaughterhouse which appendant to Homs (15) samples. The pathogenic agent (Clostridium chauvoei) was isolated from Hama's slaughterhouse only in one sample while in Homs and Rastan slaughterhouses we haven't any positive sample. The sensitivity test for eight antibiotics on positive sample to delimit the suitable antibiotic to treat black leg disease was carried out. 


\section{INTRODUCTION

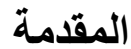

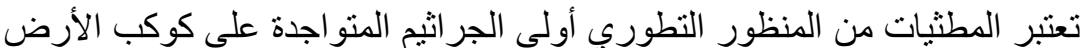

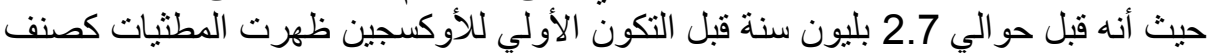

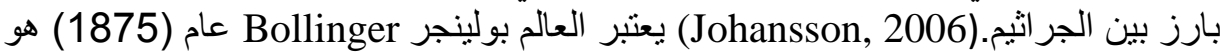
أول من وصف مطنية مرضية و هي مطنية شوفاي

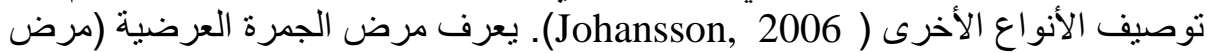

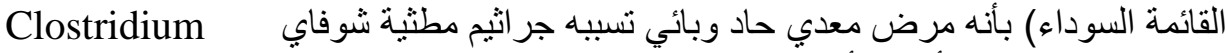

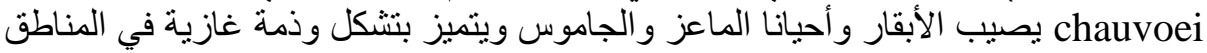

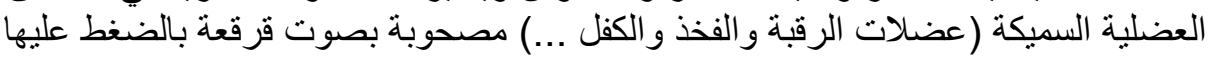

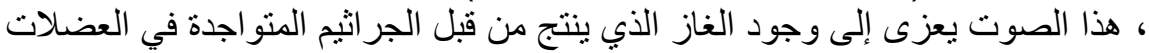
المصابة (Floyd and James, 1994)

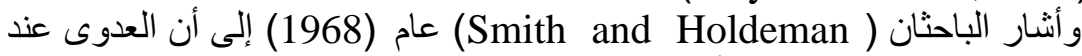

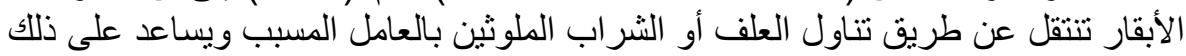

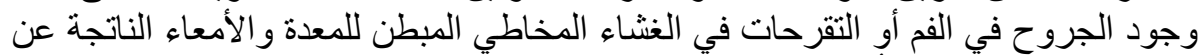

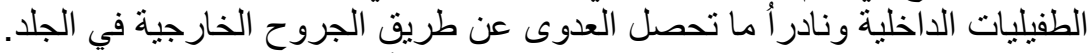

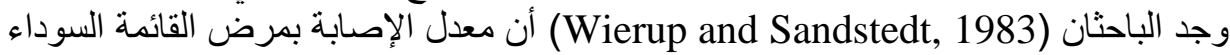

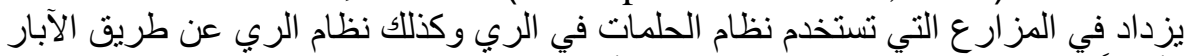

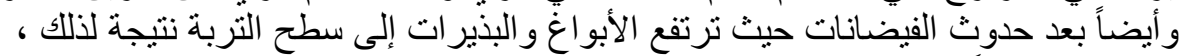

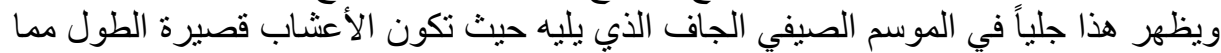

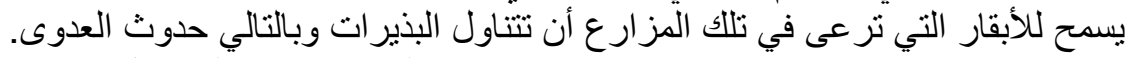

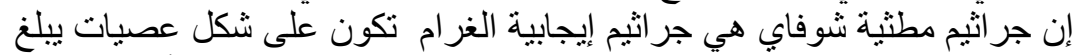

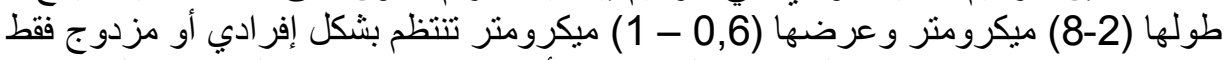

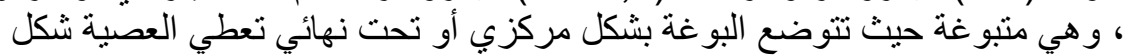

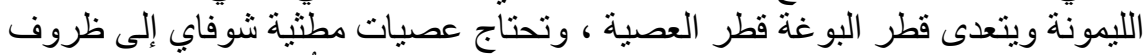

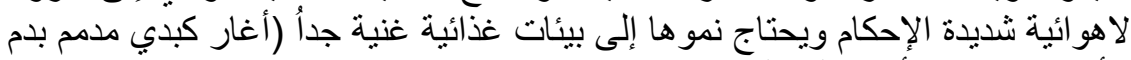
الأغنام) و هذا ما أنشار إليه الباحثُون (Sutter, et al., 1985).

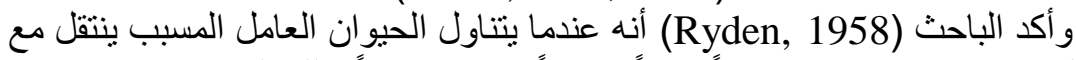

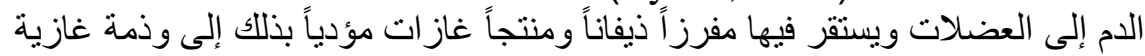

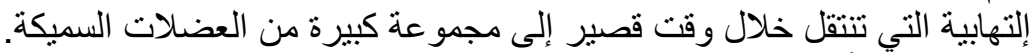

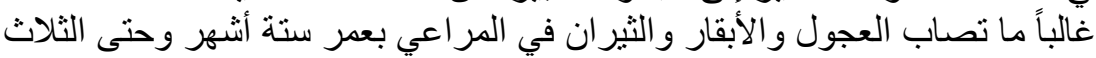

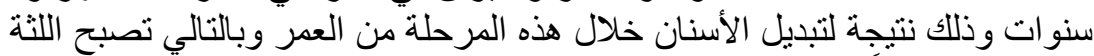

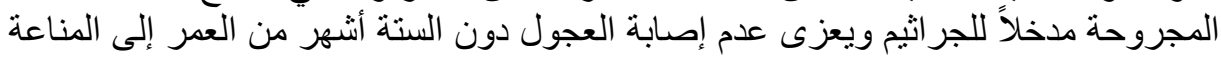

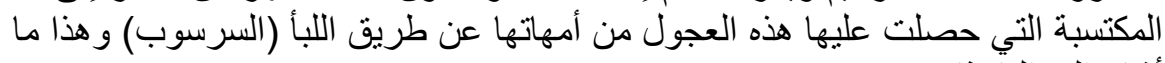
أثنار إليه البآحثان (Smith and Williams, 1984).

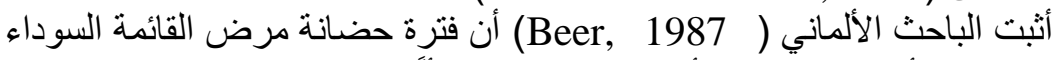
تتراوح من (1- 3) أيام تظهر بعدها أعر اض المرض المر فجأَّ. 


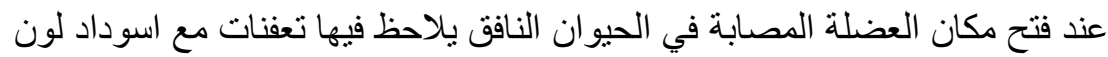

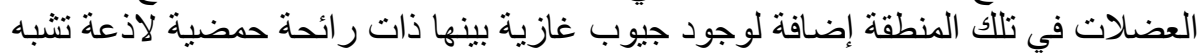

رائحة الزبدة الفاسدة و هذا ما أثنار إليه الباحث (Acha and Szyfries, 1987).

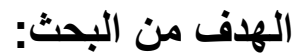

1 ـ تحديد معدل الإصابة بمرض الجمرة العرضية في الذبائح الواردة إلى مجازر المنطقة

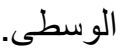

r - معرفة أفضل أنو اع الصادات الحيوية التي تؤُثر على المستعمر ات الجرثومية المعزولة من العينات الايجابية التي تم عزلها التها وتصنيفها.

\section{MATERIALS and METHODS مواد وطرائق البحث}

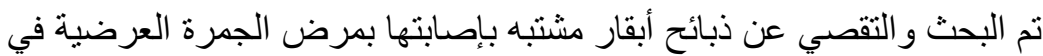

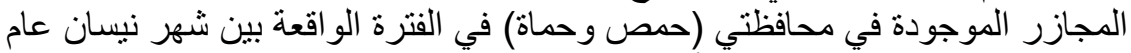

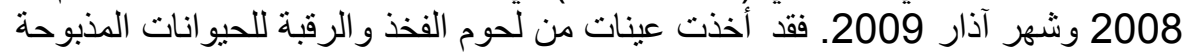

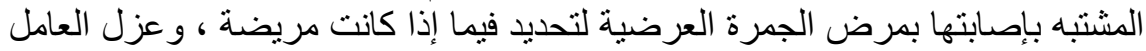

بلغ عدد العينات المفحوصة المشتبهة في مجزر حماة ( 35) عينة الرينة ، وفي مجزر حمص (25) عينة وفي مجزر مدينة الرستن التابعة لمحافظة حمص (

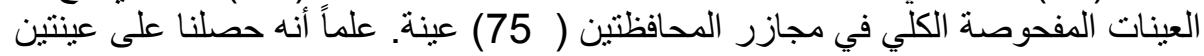

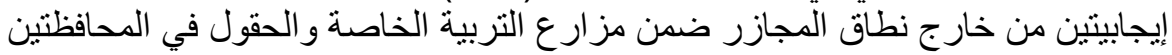

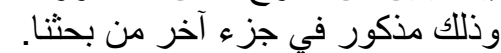

تم فحص الأعر اض السريرية للحيو ان قبل فيل الذبح حيث لاحظنا: * ارتفاع في درجة

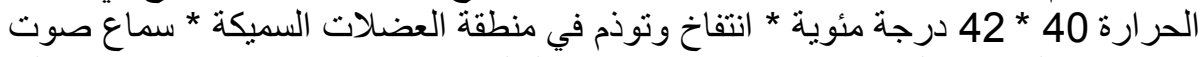

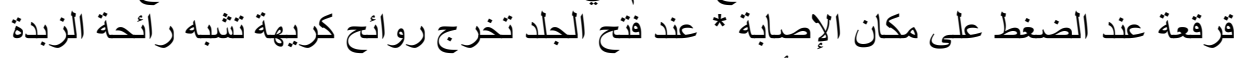
الفاسدة * تضخم العقد اللمفاوية المأخوذة من مكانة * عندان الإصابة.

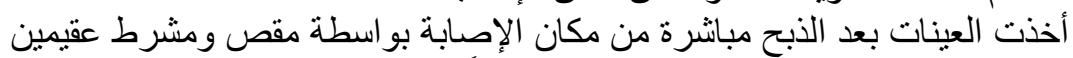

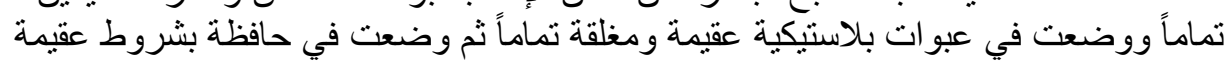

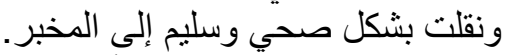

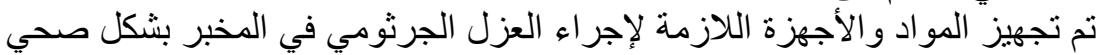

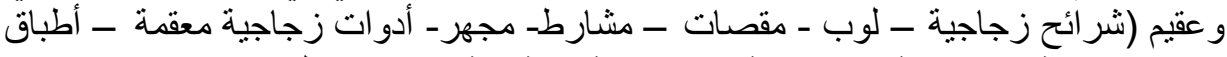

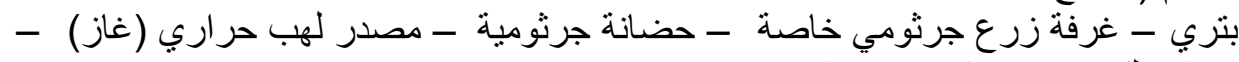

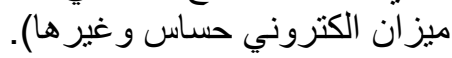

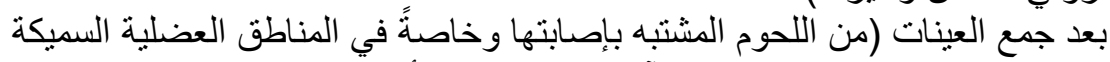

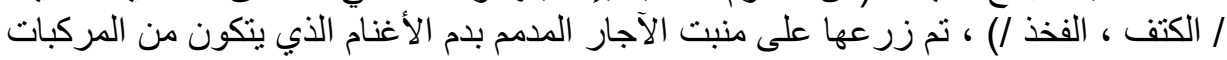

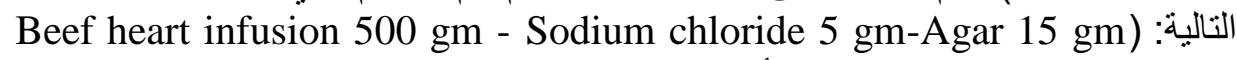
(Tryptose10 gm -

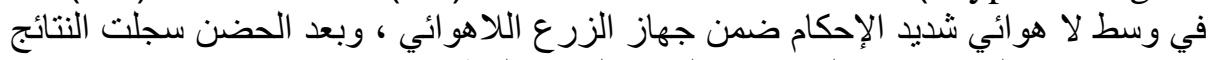

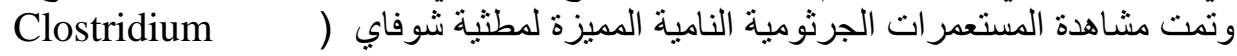
.(chauvoei 


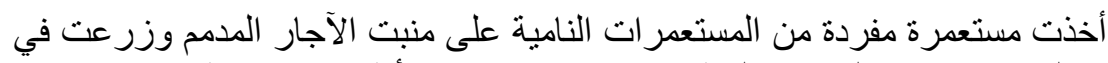

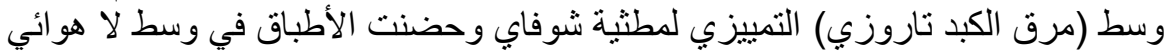

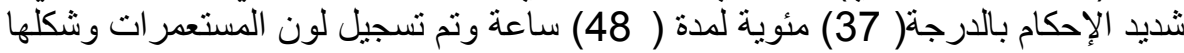

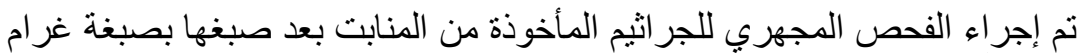

وحجمها.

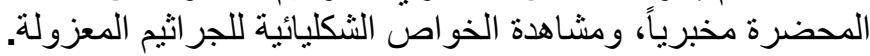

ثم أخذت مسحات من المستعمر ات الموجودة المبات في المنابت السابقة و التي كانت إيجابية

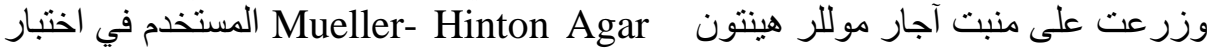
الحساسية للجر اثثم تجاه الصادات الحيوية.

\section{RESULTS}

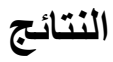

وجدت مطنية شوفاي في عينة واحدة من أصل ( 35) عينة أخذت من أبقار مشتبه

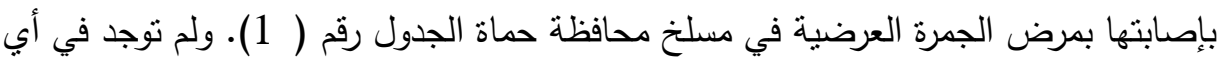

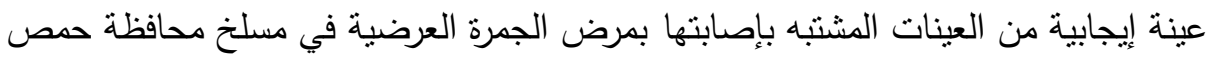
الجدول رقم (2).

كما أنه لم توجد أب عبنة إيجابية من العينات المشتبه بإصابتها بمرض الجمرة

العرضية في مسلخ مدينة الرستن الجدول رقم (3).

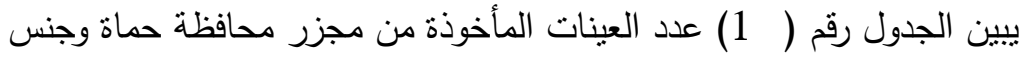

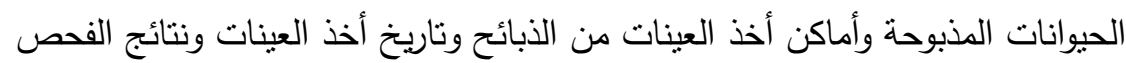

المخبري لمرض الجمرة العرضية لتلك العينات.

\begin{tabular}{|c|c|c|c|}
\hline الجنائج الفحصرة المرض العرضية & ت تاريخ أخذ العينات & المذبوحة المفيو انات & عدد العينات \\
\hline سلبية & بين شهري نيسان وحزيران & ذ - اكور & 2 \\
\hline عينة واحدة فقط & بين شهري تموز و أيلول 2008م & 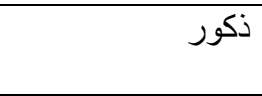 & 12 عينة \\
\hline سلبية & 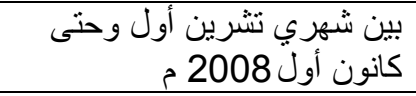 & ذكور & 16 عينة \\
\hline سلبية & بين شهري كانون الثاني و آذار & 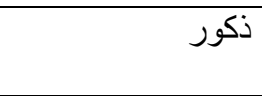 & 5 \\
\hline \multicolumn{3}{|c|}{ عدد العينات المدروسة الكلي } & 35 عينة \\
\hline
\end{tabular}

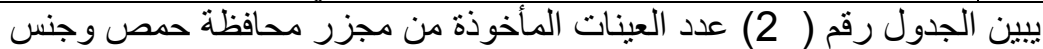

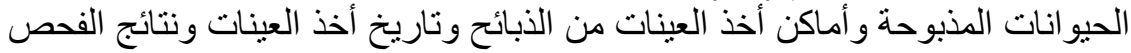
المخبري لمرض الجمرة العرضية لتلاك العينات. 
Assiut Vet. Med. J. Vol. 56 No. 124 January 2010

\begin{tabular}{|c|c|c|c|}
\hline الجمبرة ألعرضي لمرضية & تاريخ أخذ العينات & المذبوحة الحفحوصنة & المدروسية \\
\hline سلبية & بين شهري نيسان وحزير ان2008م & أنثى وذكرين & 3 عينة \\
\hline سلبية & بين شهري تموز و أيلول 2008 م & 6 إناث+ 4 ذكور & 10 عينة \\
\hline سلبية & 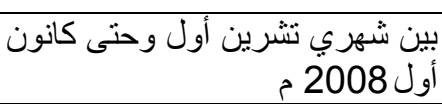 & 3ذكور +3 إناث & 6 \\
\hline سلبية & 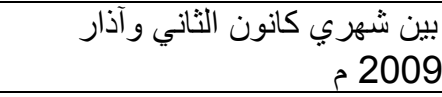 & ذكرين+4 إناث & 6 \\
\hline \multicolumn{3}{|c|}{ عدد العينات المدروسة الكلي } & 25 عينة \\
\hline
\end{tabular}

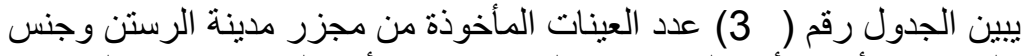

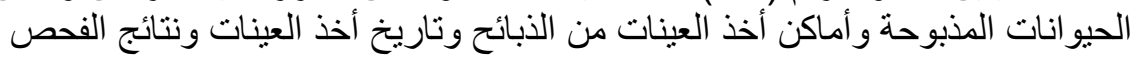
لمخبري لمرض الجمرة العرضية لتلاك العينات.

\begin{tabular}{|c|c|c|c|}
\hline لنتائج الفحص الجرة العرضبرية & تاريخ أخذ العينات & الدذبوحة الحفحوصنة & عدال العدروسة \\
\hline سلبية & 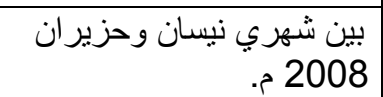 & أنثى + ذكرين & 3 عينة \\
\hline سليية & 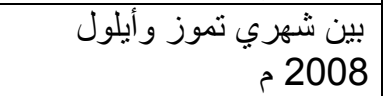 & 4 ذكور & 4 عينة \\
\hline سلبية & 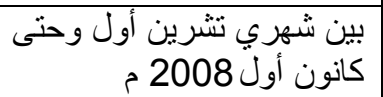 & 3 ذكور + أنثيين & 5 \\
\hline سلبية & 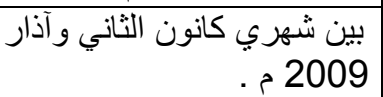 & ذكرين + أنثى & 3 عينة \\
\hline \multicolumn{3}{|c|}{ عدد العينات المدروسة الكلي } & 15 عينة \\
\hline
\end{tabular}

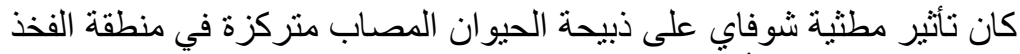

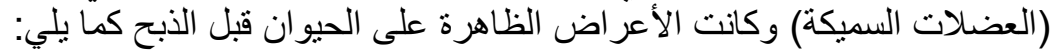

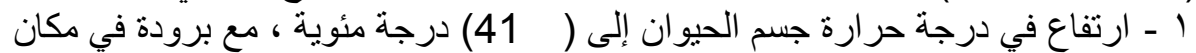
الإصنابة.

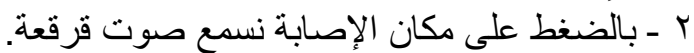

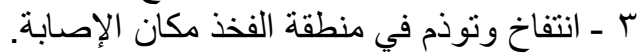

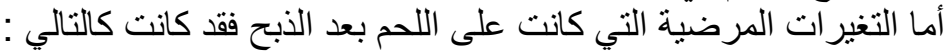

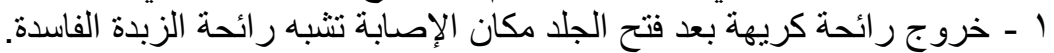

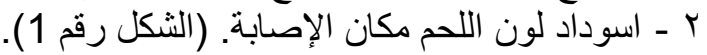
r - تشكل سو ائل التهابية وغاز الات مكان الإصابة. (الثكل رقم 1). 
Assiut Vet. Med. J. Vol. 56 No. 124 January 2010

ع - تضخم العقد اللمفاوية الموضعية وارتنشاحها بسو ائل التهابية. (الثكل رقم 2).

يبين الثكل رقم ( 1) اسوداد اللحم مكان الإصابة في فخذ الحيوان المصاب وتثكل سوائل

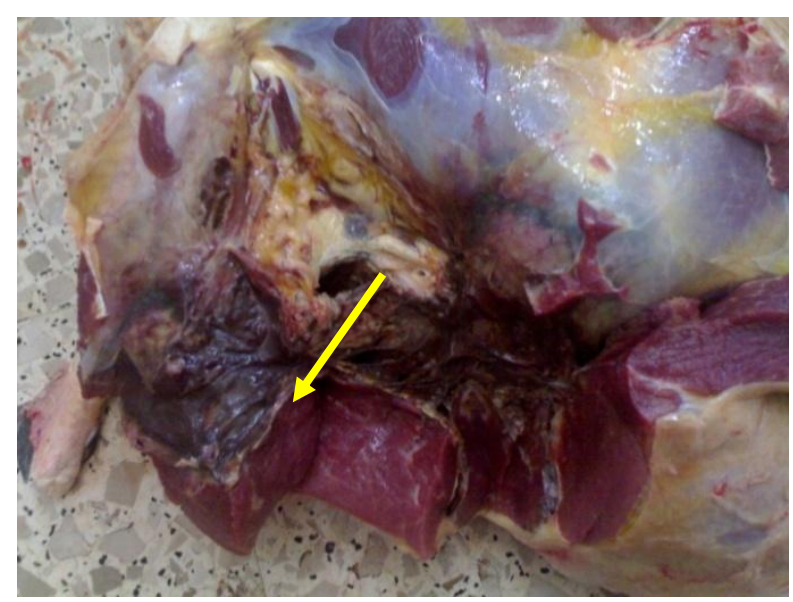

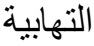

يبين الثكل رقم (2) تضخم العقد اللمفاوية المأخوذة من مكان الإصابة

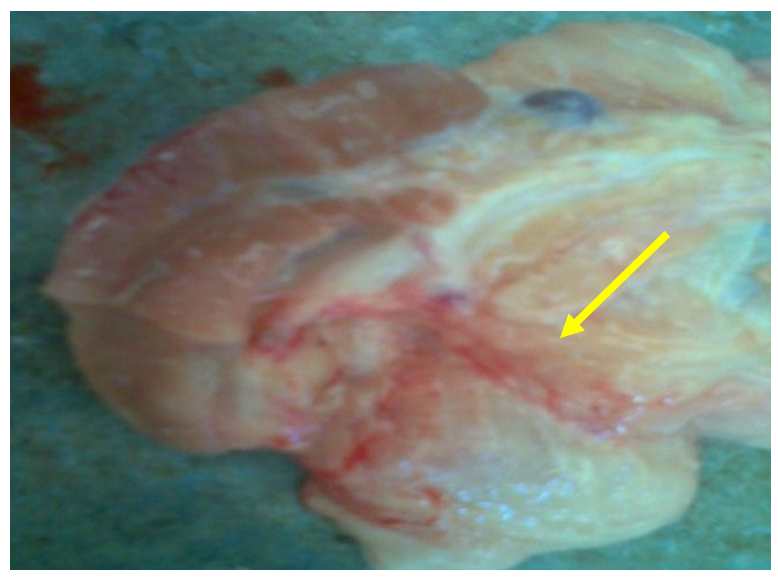

كانت نتيجة الزرع الجرثومي على منبت الآجار المدمم عبارة عن مستعمر ات جرثومية مميزة

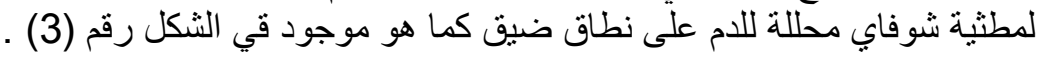

يبين الثكل رقم (3) المستعمرات المتثكلة على منبت الآجار المدمم وأماكن التحلل الدموي. 


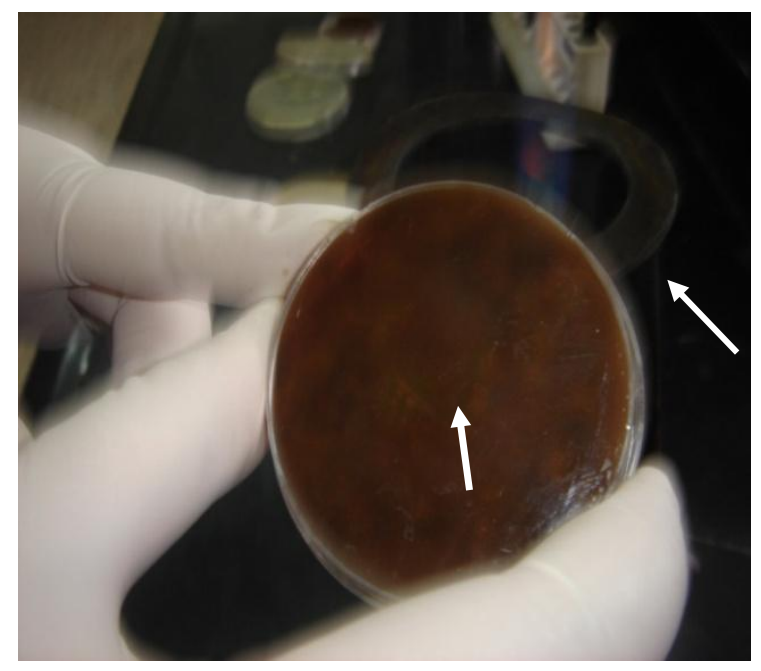

بعد إجر اء المسحة الجرثومية وصبغها بصبغة غر ام تمت مشاهدة الجر اثيم وصفاتها الثكليائية

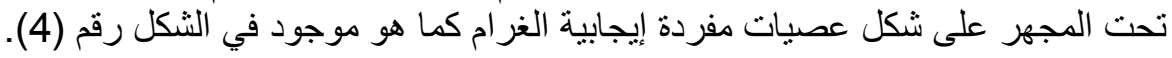

\section{يبين الثكل رقم (4) عصيات المطثية شوفاي الإيجابية الغرام المفردة}

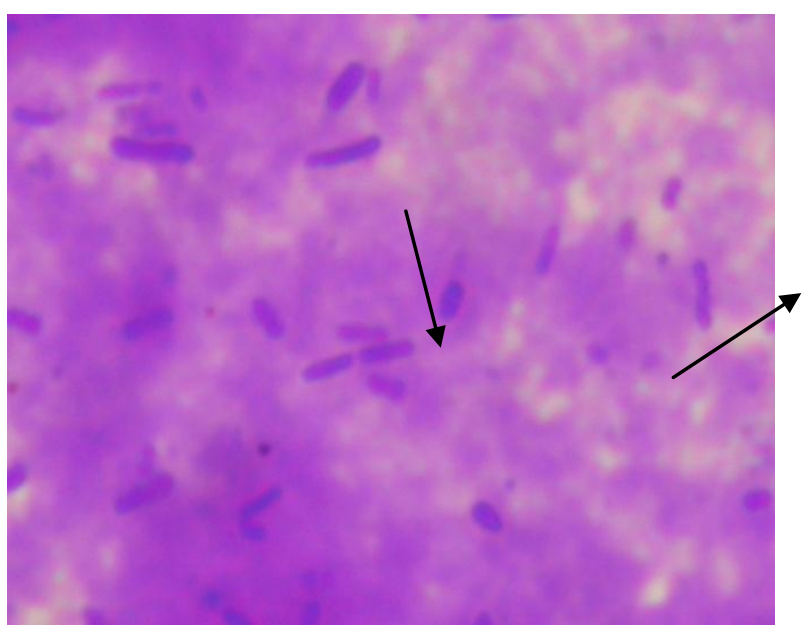

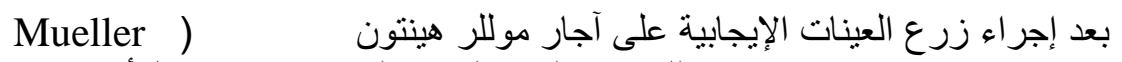
(Hinton Agar

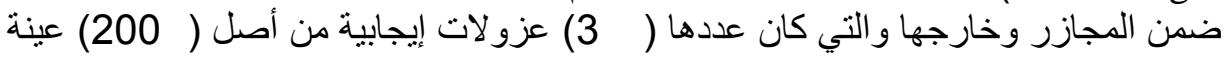

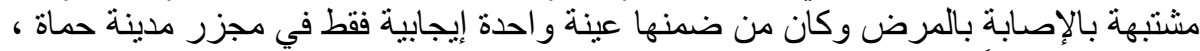

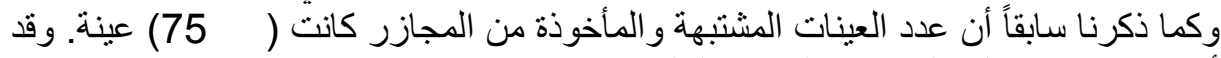
أجري الاختبار على الصادات الحيوية التالية : 
Assiut Vet. Med. J. Vol. 56 No. 124 January 2010

\begin{tabular}{|c|c|c|}
\hline تركيزه & | رمزه & اسم الصـاد الحيوي \\
\hline $\mathrm{mg} 10$ & $P$ & البنسلين \\
\hline mg 16 & $E$ & أرثرومايسين \\
\hline $\mathrm{mg} 6$ & CPR & سبيروفلوكساسين \\
\hline $\mathrm{mg} 10$ & GM & جنتاميسين \\
\hline $\mathrm{mg} 30$ & $T$ & أوكسي نتر اسكلين \\
\hline $\mathrm{mg} 10$ & $\mathrm{CT}$ & كولستين \\
\hline $\mathrm{mg} 10$ & $S$ & ستربتومايسين \\
\hline mg 10 & AM & أمبيسلين \\
\hline
\end{tabular}

كانت نتائج الاختبار على العينات الإيجابية الثناثة حسب منطقة منع النمو كما يلي

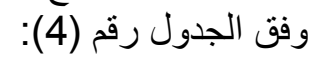
يبين الجدول رقم ( 4) بنتائج اختبار الحساسية للصادات الحيوية على العزولات

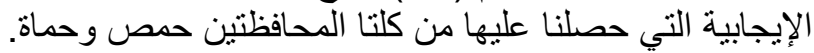

\begin{tabular}{|c|c|c|c|}
\hline \multicolumn{3}{|c|}{ رمز العينات الإيجابية المعزولة } & اسم الصاد الحيوي \\
\hline 3(من محافظةحمص) & 2 & 1 (من مجزر حماة ) & \\
\hline+++ & +++ & +++ & البنسلين \\
\hline++ & ++ & ++ & أرثزو مايسين \\
\hline+++ & +++ & +++ & أمبيسلين \\
\hline \pm+ & \pm+ & \pm+ & سييرو فلو كساسين \\
\hline- & - & - & جنتاميسين \\
\hline \pm++ & \pm++ & \pm++ & أوكسي تتر اسكلين \\
\hline - & - & - & كوليستين \\
\hline - & - & - & سترييتو مايسين \\
\hline
\end{tabular}

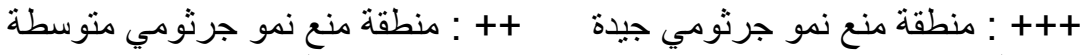
+ منطقة منع نمو جرثومي ضنعيفة

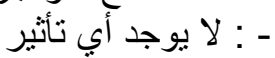

\section{DISCUSSION}

\section{المناقشة}

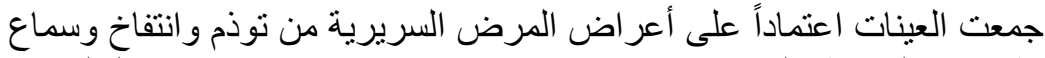

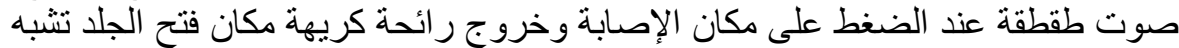
رائحة الزبدة الفاسدة و هذا ما يتو افق مع الباحث (19) (Forbes and Sahm, 1998).

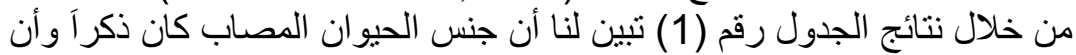

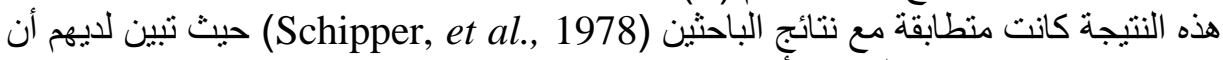
نسبة الإصابة عند ذكور التسمين أكبر من الإناث. 
أيضاً من خلال الجدول رقم ( 1) وجدنا أن الإصـابة بمرض الجمرة العرضية

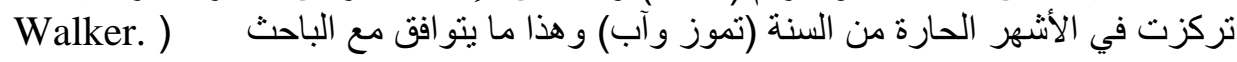

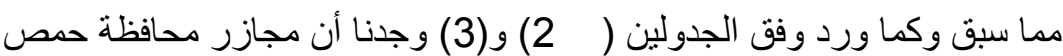

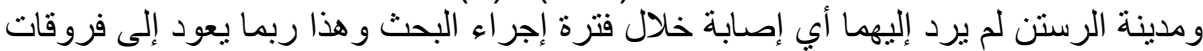

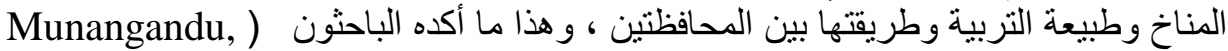

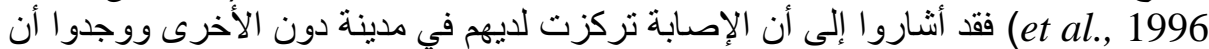

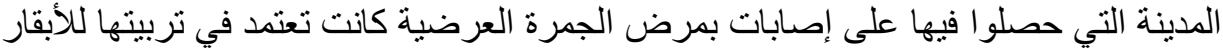

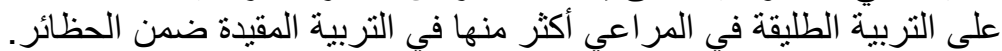

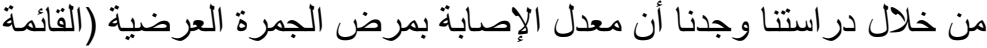

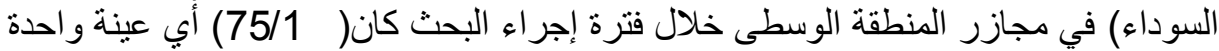

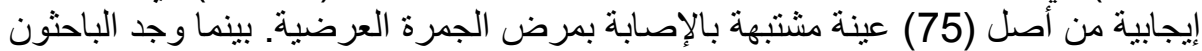
(Azechi, et al., 1962) كانت (\%)

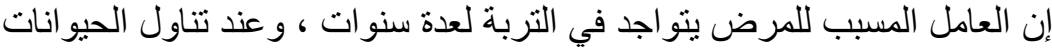

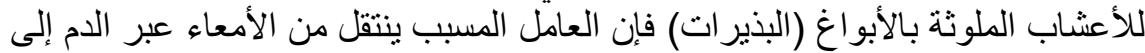

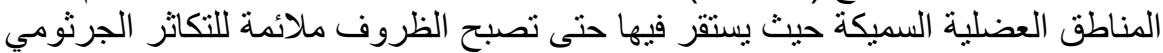

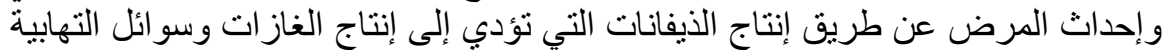
Dwight )

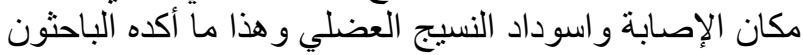
. (and Yuan,1999

تعتبر اللحوم المصابة بمرض الجمرة العرضية غير صالحة للاستهلاك البشري لأنها

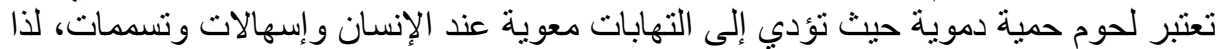

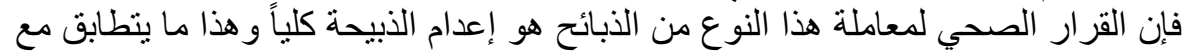
الباحثنان (Gakuen and Musashi, 2004). وبالتالي تأثيره السلبي لبس فقط على المستهلك و إنما أيضاً على الجانب الاقتصادي

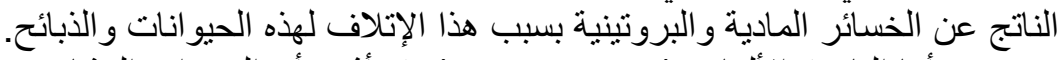

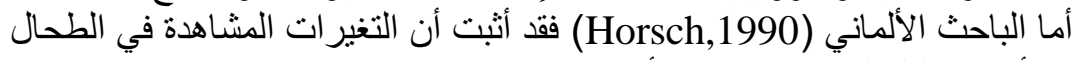

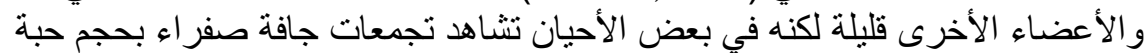

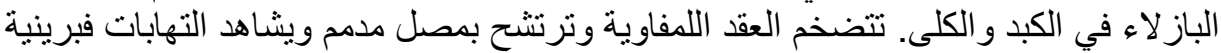

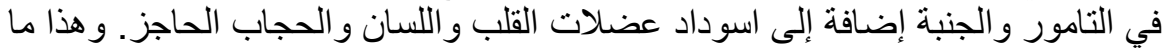
تطابق تماماً مع نتائج بحثنا.

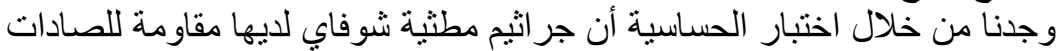

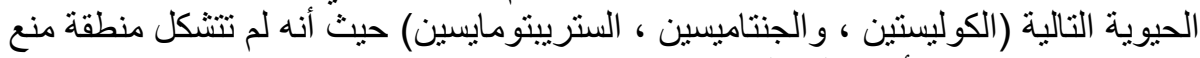

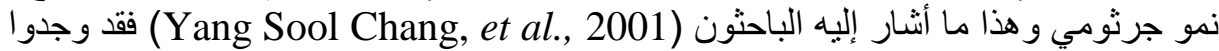

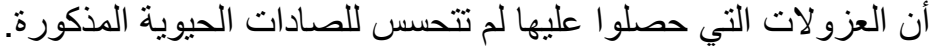

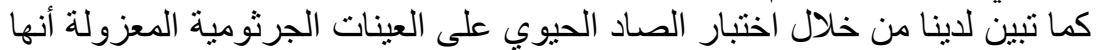

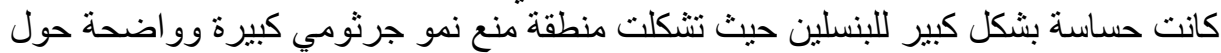

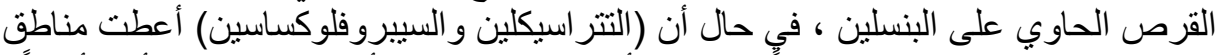
منع نمو جرثومي تعتبر جيدة نوعاً ما ولكنها أقل من البنسلين و الأمبيسلين و هذا ما أكده أيضاً الباحثون (Yang Sool Chang, et al., 2001). 


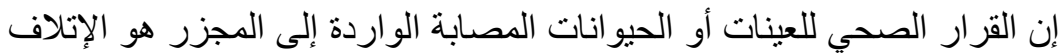

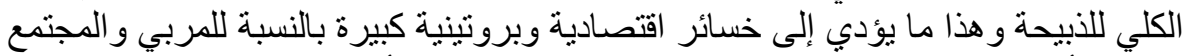

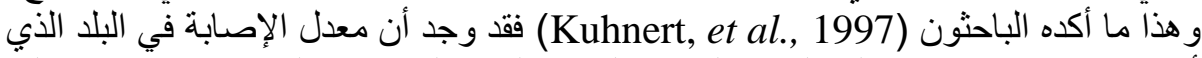

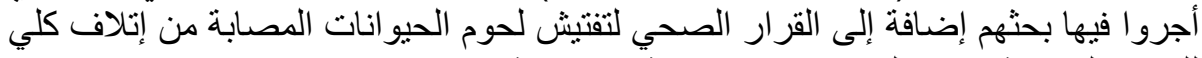
لللبائح المصابة يؤدي إلى خسائر اقتصادية وبروتئينة الفينة كبيرة.

\section{CONCLUSIONS and SUGGESTIONS الاستنتاجات والمقترحات}

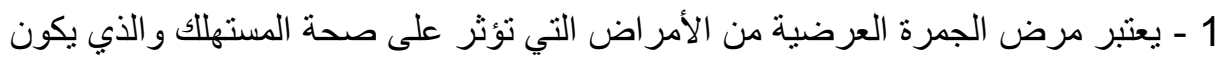

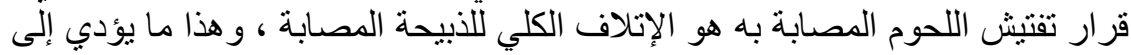

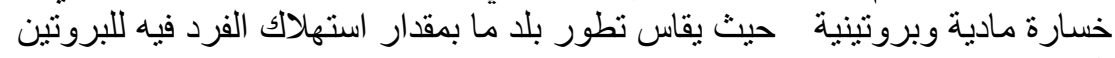
الحيو اني.

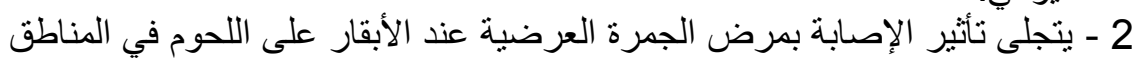

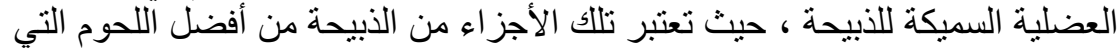

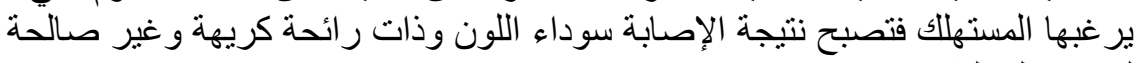
لمتنهالك البشري.

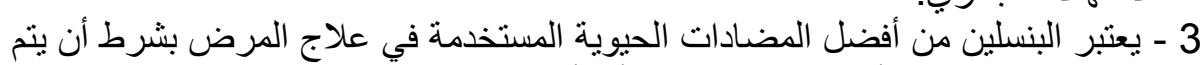

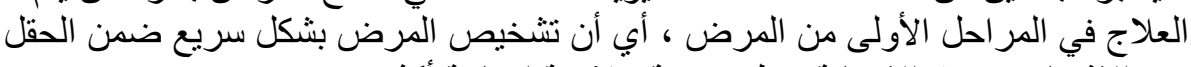

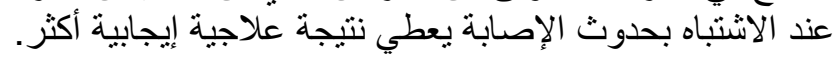

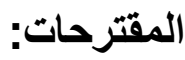

1 - مر اعاة تطبيق قو اعد الصحة العامة ضمن المجازر من خلال الصحة الثخصية و التعقيم

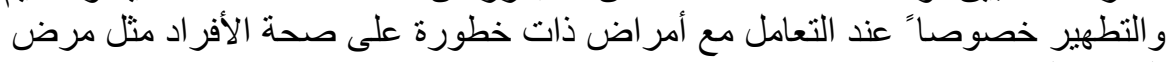
الجمرة العرضية.

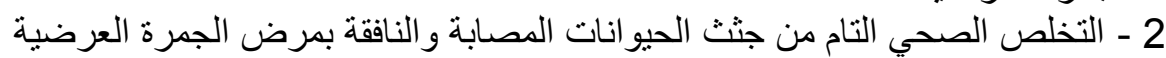

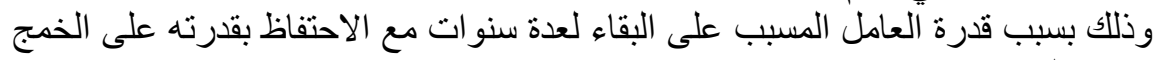

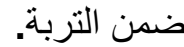

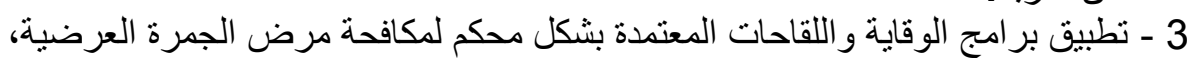

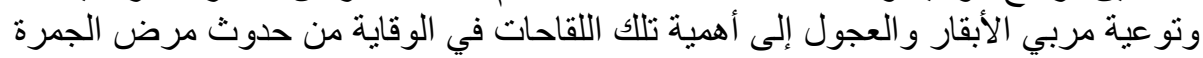

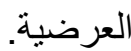
4 - اتخاذ الإجر اءات الضرورية للحد من الآثار الضارة للفيضانات و السيول والسيطرة على العلى

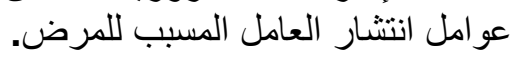

\section{REFERENCES}

Azechi, H.; Seto, K.; Mukawa, K. and Suzuki, K. (1962): Studies on the potency test of blackleg vaccine. Jpn. J. Vet. ci 24: 267-275. 
Acha, PN. and Szyfries, B. (1987): Zoonoses communicable diseases common to man and animals, $2^{\text {nd }}$ ed, Pan America Health organisation, Washington.

Beer, J. (1987): Infekhonskrankheiten der Haustiere. 3; Auflage, VEB Gustav Fischer Verlage Jena.

Dewight, C.H. and Yuan, C.Z. (1999): Veterinary Microbiology, black well science. inc. Usa. pp. 233-245.

Floyd, G. and James, J. (1994): Black leg and other clostridial diseses in cattle Alabama Cooperative Extension System. ANB -0888. Auburn, Alabama.

Forebes, B.A. and Sahm, D.F. (1998): Weissfeld bacteriology laboratory considerations in: Bailey and scott's diagnostic microbiology. 10 th ed. st Louis.

Gakuen, and Musashi, M. (2004): Department of bacterial pathogenesis and infection control, National institute of infectious diseases, Tokyo 208- 0011, japan.

Horsch, F. (1990): Immunprophylaxe bei Nutzitieren. Gustav Fischer Verlag Jena.

Johansson, A. (2006): Clostridium perfringes the causal agent of necrotic enteritis in poultry doctoral thesis; Sweedish University of Agrycultural Sciences. pp; 12-14.

Kuhnert, P.; Krampe, M.; Capul, SE.; Frey, J. and Nicolet, J. (1997): Identification of clostridium chauvoei in cultures and clinical material from black leg using PCR. Vet Microbial 57: 291-298.

Munang'andu, HM.; Muyoyeta, PM.; Mweene, AS. and Kida, H. (1996): Bovine clostridial infections in Zambia. Jpn J. Vet. Res. 44: 175-178.

Ryden, $R$. (1958): Development of anaerobic fermentation processes: acetone- butanol. In biochemical Engineering ed. Steel J.R pp.123-128. London: Heywood.

Schipper, IA.; Kelling, CL. and Mayer, J. (1978): Effect on immune response in calves vaccinated against Clostridium chauvoei infection (Blackleg). Vet. Ret. 100: 90-91.

Smith, L.D.S. and Williams, B.L. (1984): Clostridiumchauvoei. In the pathogenic anaerobic bacteria 3th edn, pp 164-175 Springfield: Charles C. Thomas.

Smith, L.D.S. and Holdeman, L.N. (1968): Clostridium chauvoei, In the pathogenic anaerobic bacteria pp, 361-373. Springfield: Charles C. Thomas. 
Sutter, V.L.; Citron, D.M.; Edelstein, M.A.C. and Fine gold, S.M. (1985): Wadsworth anaerobic bacteriology Manual. $4^{\text {th }}$ edition. Star, Belmont USA.

Wierup, M. and Sandstedt, K. (1983): Blackleg and pulpy kidney disease -two clostridim diseases in Sweden, 35: 23-24 (In Sweedish).

Walker, P.D. (1990): Clostridium, in Carter and J.R. Cole ,J.R (ed) .Diagnostic procedures in Veterinary bacteriology and mycology, $5^{\text {th }}$ ed. Academic press, San. Diego., Calif.; P. 229-251.

Yang Sool Chang; Kyoo Tae Kim; Young Hoan Kim; SoonTae KiM; Jae Cheul Do; Dae Won Kim and Bong Hwan Kim (2001): Prevalence and factors associated with Blackleg outbreak in north western Gyeongbuk province. Korean J. Vet. Serv. 25 (1):75-86. 